\title{
Effects of peripheral neuropathy on exercise capacity and quality of life in patients with chronic obstructive pulmonary diseases
}

\author{
Gaye Ulubay ${ }^{1}$, Sevinc Sarinc Ulasli ${ }^{1}$, Serife Savas Bozbas ${ }^{1}$, Tugce Ozdemirel' ${ }^{1}$, Metin Karatas ${ }^{2}$
}

1Department of Pulmonary Diseases, Faculty of Medicine, Baskent University, Ankara,
Turkey
2Department of Physical Medicine and Rehabilitation, Faculty of Medicine, Ankara,
Turkey

Submitted: 20 July 2010

Accepted: 28 December 2010

Arch Med Sci 2012; 8, 2: 296-302

DOI: 10.5114/aoms.2012.28557

Copyright (c) 2012 Termedia \& Banach

\author{
Corresponding author: \\ Serife Savas Bozbas MD \\ Department \\ of Pulmonary Diseases \\ Baskent University \\ Faculty of Medicine \\ 5. cadde No: 48 \\ 06490 Bahcelievler \\ Ankara, Turkey \\ Phone: 03122122912 \\ Fax: 03122341216 \\ E-mail: serifesb@gmail.com
}

\begin{abstract}
Introduction: Chronic obstructive pulmonary diseases (COPD) have some systemic effects including systemic inflammation, nutritional abnormalities, skeletal muscle dysfunction, and cardiovascular, skeletal and neurological disorders. Some studies have reported the presence of peripheral neuropathy (PNP) at an incidence of $28-94 \%$ in patients with COPD. Our study aimed to identify whether PNP affects exercise performance and quality of life in COPD patients.

Material and methods: Thirty mild-very severe patients with COPD (male/female $=29 / 1$, mean age $=64 \pm 10$ years) and 14 normal subjects (male/female $=11 / 5$, mean age $=61 \pm 8$ years) were included in the present study. All subjects underwent pulmonary function testing (PFT), cardiopulmonary exercise testing, electroneuromyography and short form 36 (SF-36).

Results: Peak oxygen uptake $\left(\right.$ PeakVO $\left._{2}\right)$ was lower in COPD patients $(1.15 \pm 0.53 \mathrm{l} / \mathrm{min})$ than healthy subjects $(2.02 \pm 0.46 \mathrm{l} / \mathrm{min})(p=0.0001)$. There was no PNP in healthy subjects while 16 (53\%) of the COPD patients had PNP. Forced expiratory volume in $1 \mathrm{~s}\left(\mathrm{FEV}_{1}\right)$ and PeakVO $\mathrm{O}_{2}$ were significantly different between patients with PNP and those without ( $p=0.009, p=0.03$ respectively). Quality of life of patients with PNP was lower than that of patients without PNP $(p<0.05)$.

Conclusions: The present study demonstrates the exercise limitation in COPD patients with PNP. Thus, presence of PNP has a poor effect on exercise capacity and quality of life in patients with COPD. Furthermore, treatment modalities for PNP can be recommended to these patients in order to improve exercise capacity and quality of life.
\end{abstract}

Key words: chronic obstructive pulmonary diseases, peripheral neuropathy, exercise capacity, quality of life.

\section{Introduction}

Chronic obstructive pulmonary diseases (COPD) are mainly characterized by the presence of airflow limitation because of airway inflammation and remodeling. Parenchymal destruction and the development of emphysema are often associated with COPD in many patients [1]. Furthermore, COPD has many important systemic effects during the natural course of disease secondary to multiple factors such as systemic inflammation, 
oxidative stress, and hypoxemia [2]. Some of these effects are nutritional abnormalities, skeletal muscle dysfunction, anemia and other abnormalities including cardiovascular, skeletal and neurological disorders [3].

Exercise limitation is a common problem in COPD patients which negatively influences healthrelated quality of life [4]. To date, ventilatory insufficiency, increased ventilatory requirement, and skeletal muscle dysfunction secondary to multiple factors have been reported as the main causes of exercise limitation in COPD patients [5].

Several studies have reported that peripheral neuropathy (PNP) could occur at an incidence of $28-94 \%$ in patients with COPD [6-9]. Smoking, long lasting hypoxia, and age have been found to be contributing factors for the development of PNP in COPD patients [6-8]. However, the clinical importance of PNP is still unclear in these patients. So far, effects of PNP on exercise limitation in COPD patients have not been investigated in the literature according to our knowledge. Based on the above, we hypothesized that peripheral neuropathy can play a role as one of the factors limiting exercise capacity in COPD patients.

For this purpose, we investigated the relationships among peripheral neuropathy, exercise capacity, and quality of life in patients with mild to very severe COPD and normal subjects.

\section{Material and methods}

\section{Study population}

Thirty stable patients with mild to very severe COPD $($ male $/$ female $=29 / 1$ mean age $=64 \pm 10$ years) and 14 healthy volunteer subjects (male/ female $=11 / 3$, mean age $=61 \pm 8$ years) were enrolled in this cross-sectional study. Diagnosis of COPD was based on current Global Initiative for Chronic Obstructive Lung Disease (GOLD) guidelines [1]. At the baseline, $6(20 \%)$ of the patients were in mild stage, 11 (36.7\%) were in moderate stage, $11(36.7 \%)$ were in severe stage, while $2(6.7 \%)$ were in very severe stage of the disease. Patients with post-bronchodilator forced expiratory volume in $1 \mathrm{~s}\left(\mathrm{FEV}_{1}\right)<80 \%$ of the predicted value and $\mathrm{FEV}_{1} /$ forced vital capacity $(\mathrm{FVC})<70 \%$ were included in the study [10]. All COPD patients were ex-smokers and all healthy subjects were nonsmokers in this study. Patients with a history of diabetes mellitus, alcoholism, chronic renal failure, malignancy, any hereditary disorders affecting peripheral nerves, intake of any neurotoxic drug, or history of any traumatic lesion affecting peripheral nerve functions, and patients who were unable to pedal a cycle ergometer, as well as active smokers, were all excluded from the study.

In our study population, all mild to very severe COPD patients were receiving inhaled long-acting $\beta_{2}$-agonists and/or anticholinergic agents and/or theophylline (oral route). Fourteen of the patients were receiving additional inhaled corticosteroids.

All subjects performed pulmonary function testing including dynamic and static lung volumes, cardiopulmonary exercise testing (CPET), electrophysiological studies (electroneuromyographic - ENMG), and the Short Form-36 (SF-36) questionnaire. All subjects were informed and signed the patient's consent form. Sixteen COPD patients with PNP in the stable period (group 1), 14 COPD patients without PNP in the stable period (group 2) and 14 healthy subjects without smoking history as a control group (group 3) were included in the study.

\section{The Short Form-36 questionnaire}

The Short Form-36 (SF-36) questionnaire is a measure of general quality of life $(\mathrm{QOL})$ that has been validated in patients with dilated cardiomyopathy. This questionnaire has 36 questions to assess the patient's ability to perform vigorous activities and activities of daily living and to participate in social, family, and occupational activities. Eight scales are used to describe domains of physical function, social function, physical and emotional role function, mental health, bodily pain, vitality, and general health perception. The physical and mental components of these scales can be combined into physical and mental composite scores. The scores are recorded on a scale ranging from zero to 100; higher scores correspond to a more favorable QOL. Responses to the SF-36 were scored by means of a computer algorithm [11].

\section{Pulmonary function testing}

Spirometry was performed prior to exercise testing. A clinical spirometer (SensorMedics Vmax spectra 229, Bilthoven, The Netherlands) was used for all assessments, and a laboratory technician demonstrated each respiratory maneuver for the subject before testing. Each subject performed a maximal expiratory flow maneuver in the sitting position. The $\mathrm{FEV}_{1}$ and FVC were measured, and the $\mathrm{FEV}_{1} / \mathrm{FVC}$ ratio was then calculated. Patients were coached by an experienced technician to perform forced expirations until 3 acceptable measurements were obtained and the best result was recorded. Each recorded result was expressed as a percentage of the predicted value for that parameter. Total lung capacity (TLC) was measured by the multiple nitrogen washout method $[12,13]$. The GOLD criteria were used to classify severity of COPD [12].

\section{Cardiopulmonary exercise testing}

The CPET was performed using a cycle ergometer (ergo-metrics 900, SensorMedics ${ }^{T M}$, Bilthoven, The Netherlands). Subjects were told not to eat or 
drink for $2 \mathrm{~h}$ before the test. The gas analyzer was calibrated before each test with 2 standardized gas mixtures $\left(26 \% \mathrm{O}_{2}+\right.$ balanced $\mathrm{N}_{2}$ and $4 \% \mathrm{CO}_{2}+16 \%$ $\mathrm{O}_{2}+\mathrm{N}_{2}$ ). A facemask connected to a low-resistance unidirectional valve (Rudolph Face Mask for Exercise Testing $^{T M}$; Hans Rudolph Inc., Kansas City, MO, USA) was placed on the subject's face without leakage. The incremental exercise testing protocol consisted of a 3-min baseline period, followed by a 3-min warm-up period (up to $60 \mathrm{rpm}$ pedaling), and then the work rate was increased by $10 \mathrm{~W}$ for each minute periodically. The data were recorded using an automated exercise testing system (Desktop Diagnostics/CPX; Medical Graphics Corporation, St. Paul, MN, USA). The maximum performed work rate that a subject sustained for 20 to $30 \mathrm{~s}$ was recorded. Each subject's electrocardiogram, arterial pressure, and oxygen saturation were monitored continuously during the test. Peak oxygen uptake (peak $\mathrm{VO}_{2}$ ), peak $\mathrm{CO}_{2}$ output, and $\mathrm{VE} / \mathrm{VCO}_{2}$ were all recorded. All values were obtained from continuous 10-s averages [14].

\section{Electrophysiological study}

Electrodiagnostic examination was performed using the Synergy (Medelec, Surrey, UK) EMG system. Limb temperature was maintained above $32^{\circ} \mathrm{C}$ using a warm compress if needed during the nerve conduction studies. Electrodiagnostic tests included conventional motor and sensory nerve conduction studies in right upper and bilateral lower limbs, determination of minimal F-wave latency, $\mathrm{H}$-reflex testing from the soleus muscle and blink reflex testing from orbicularis oculi muscles.

Table I. Demographic, clinical characteristics and SF-36 life quality questionnaire parameters of the patients and control subjects

\begin{tabular}{|c|c|c|c|}
\hline Parameter & $\begin{array}{l}\text { COPD } \\
\text { group } \\
(n=30)\end{array}$ & $\begin{array}{l}\text { Healthy } \\
\text { subjects } \\
(n=14)\end{array}$ & Value of $p$ \\
\hline \multicolumn{4}{|l|}{ Sex } \\
\hline Female & 1 & 5 & \\
\hline Male & 29 & 9 & \\
\hline Age [years] & $64 \pm 10$ & $61 \pm 8$ & 0.38 \\
\hline $\mathrm{BMI}\left[\mathrm{kg} / \mathrm{m}^{2}\right]$ & $25.2 \pm 4.3$ & $28.7 \pm 3.5$ & 0.014 \\
\hline Peak $\mathrm{VO}_{2}[\mathrm{l} / \mathrm{min}]$ & $1.1 \pm 0.5$ & $2.02 \pm 0.5$ & 0.0001 \\
\hline $\mathrm{FEV}_{1}[\mathrm{I}]$ & $1.6 \pm 0.7$ & $3.9 \pm 0.8$ & 0.0001 \\
\hline $\mathrm{FEV}_{1}(\%$ predicted $)$ & $56.1 \pm 21.8$ & $123.9 \pm 15.9$ & 0.0001 \\
\hline FVC (\% predicted) & $97.0 \pm 23.0$ & $130.8 \pm 16.7$ & 0.0001 \\
\hline $\mathrm{FEV}_{1} / \mathrm{FVC}$ & $45.3 \pm 13.6$ & $79.6 \pm 6.8$ & 0.0001 \\
\hline $\begin{array}{l}\mathrm{FEF}_{25-75} \\
\text { (\% predicted) }\end{array}$ & $18.6 \pm 13.9$ & $102.9 \pm 28.3$ & 0.0001 \\
\hline TLC (\% predicted) & $98.8 \pm 23.5$ & $126.6 \pm 13.2$ & 0.001 \\
\hline PNP & $16(53 \%)$ & 0 & 0.0001 \\
\hline
\end{tabular}

Motor nerve conduction studies included right median and ulnar, bilateral peroneal and tibial nerves, using percutaneous stimulation and recording. Sensory nerve conduction studies included right superficial radial and bilateral superficial peroneal and sural nerves using percutaneous stimulation and recording. Sensory nerve action potentials (SNAPs) were recorded using antidromic technique. The $\mathrm{H}$ reflex was recorded from the soleus/gastrocnemius muscles by stimulating the tibial nerve at the popliteal fossa. Blink reflexes were recorded from the orbicularis oculi of both sides while electrical stimulation of the supraorbital nerves was applied. Measured variables were amplitudes $(\mu \mathrm{V})$ of antidromic sensory nerve action potentials (SNAPs), distal motor latencies (DMLs) (ms), amplitudes $(\mathrm{mV})$ of compound muscle action potentials (CMAPs), F-wave minimum latencies (ms), H-reflex latency (ms), amplitude and ratio of $\mathrm{H}$ response, and motor response $(M)$ amplitude $(\mathrm{mV})$.

\section{Statistical analysis}

The SPSS program (SPSS version 12.0; SPSS Inc., Chicago, IL, USA) was used for the statistical analyses. Continuous data are presented as means \pm standard deviation. The unpaired Student $t$ test was used to analyze the effects of continuous variables. Pearson $\chi^{2}$ test was employed for the analysis of categorical variables and results are expressed as $n$ and $\%$. More than two groups in which variables were normally distributed with homogeneous group variances were compared by using one-way analysis of variance (ANOVA) and Tukey test was used for post-hoc analysis. A $p$ value below 0.05 was considered significant.

The study was approved by the institutional ethical committee. The research protocol also complies with the Helsinki Declaration of 2000.

\section{Results}

Demographic and clinical characteristics of the patients and the healthy subjects are presented in Table I. All of the patients with COPD had smoking history, with a mean value of $45.9 \pm 19.2$ pack years. With regard to SF-36 life quality assessment, physical activity, difficulty in role playing, general health and vitality parameters were found to be lower in patients with COPD than in control subjects (Table I). Of the SF-36 life quality questionnaire parameters, physical functioning (PF), role-physical (RP), vitality (VT) and social functioning (SF) were found to be significantly lower in COPD patients than in control subjects $(p<0.05)$ (Table I). Electrophysiological studies (ENMG) were performed in all of the study population and PNP was identified in 16 (53\%) of 30 patients with COPD. Eight of the patients had mild axonal sensorimotor neuropa- 


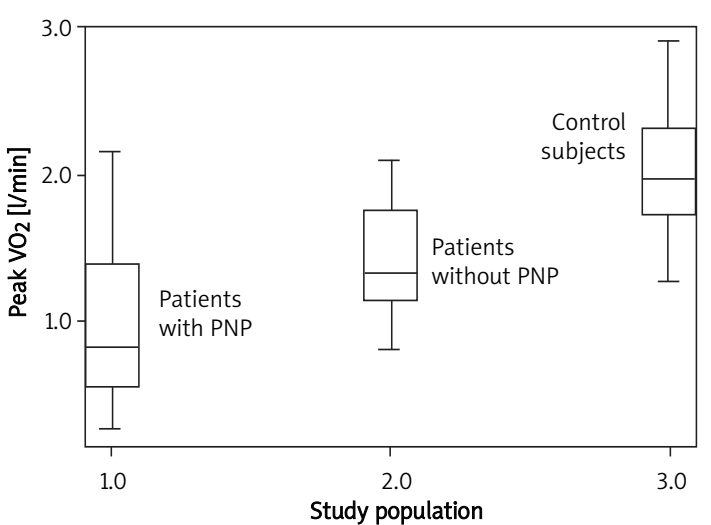

Figure 1. Peak $\mathrm{VO}_{2}$ values of the study population

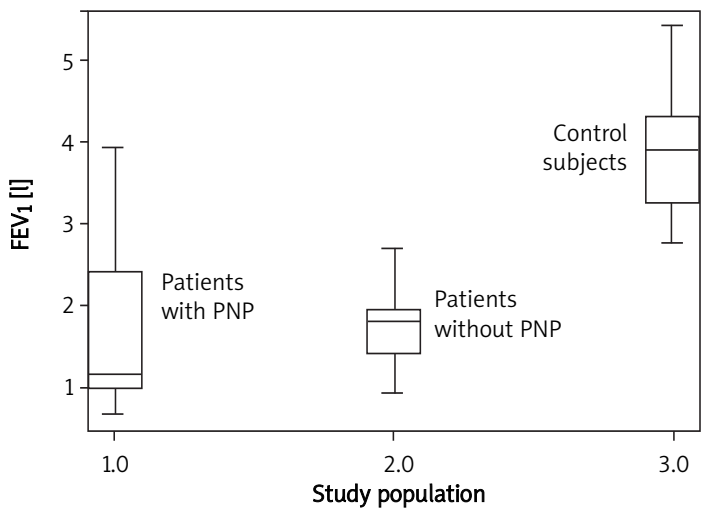

Figure 2. $\mathrm{FEV}_{1}$ values of the study population

cle dysfunction [18], tissue hypoxia [19] and the bone marrow $[2,20]$. To the best of our knowledge, there is no study researching the clinical effect of PNP in COPD patients. In the present study, we investigated the effects of PNP on exercise capacity and quality of life in mild to very severe COPD patients.

In our study population, we had a much higher number of males than females in the COPD group. In a recent study the COPD rate was reported as four times higher in males than females in our country (80 of 1160 subjects had a diagnosis of COPD). Total smoking, biomass, and occupational exposure were also found to be overwhelmingly higher in males than in females in the same study (16.1\% and $3.9 \%$ respectively). Smoking was also at a higher rate in males than females $(57.2 \%$ and $25.5 \%$ respectively) [21]. Therefore, we suggest that this result could be attributed to higher incidence of COPD in males in our country.

In the present study peripheral neuropathy has occurred at an incidence of $53 \%$ in patients with COPD while an incidence of $28-94 \%$ was reported

Table II. Comparison of the COPD patients with and without PNP with regard to demographic and clinical characteristics and SF-36 questionnaire parameters

\begin{tabular}{|lccc|}
\hline SF-36 parameters & $\begin{array}{c}\text { COPD } \\
\text { group } \\
(n=30)\end{array}$ & $\begin{array}{c}\text { Healthy } \\
\text { subjects } \\
(n=14)\end{array}$ & Value of $p$ \\
\hline Physical functioning & $62.2 \pm 29.7$ & $87.1 \pm 17.7$ & 0.007 \\
\hline $\begin{array}{l}\text { Difficulty in role } \\
\text { playing }\end{array}$ & $53.7 \pm 42.5$ & $91.3 \pm 26.9$ & 0.005 \\
\hline Pain & $76.7 \pm 26.2$ & $81.0 \pm 19.9$ & 0.59 \\
\hline General health & $52.0 \pm 23.0$ & $69.7 \pm 15.6$ & 0.01 \\
\hline Vitality & $64.6 \pm 19.4$ & $77.8 \pm 15.0$ & 0.03 \\
\hline Social functioning & $80.5 \pm 24.5$ & $85.9 \pm 9.6$ & 0.44 \\
\hline Emotional well-being & $54.3 \pm 37.1$ & $69.0 \pm 27.6$ & 0.2 \\
\hline Mental health & $69.3 \pm 21.8$ & $71.1 \pm 13.3$ & 0.7 \\
\hline
\end{tabular}


Table III. Comparison of demographic and clinical characteristics and SF-36 questionnaire parameters among three groups

\begin{tabular}{|c|c|c|c|}
\hline Parameters & $\begin{array}{l}\text { Group } 1 \\
\text { COPD } \\
\text { with PNP } \\
(n=16)\end{array}$ & $\begin{array}{c}\text { Group } 2 \\
\text { COPD } \\
\text { without PNP } \\
(n=14)\end{array}$ & $\begin{array}{l}\text { Group } 3 \\
\text { Controls } \\
(n=14)\end{array}$ \\
\hline Age [years] & $66.4 \pm 9.3$ & $60.5 \pm 9.4$ & $61 \pm 8$ \\
\hline BMI $\left[\mathrm{kg} / \mathrm{m}^{2}\right]$ & $24.0 \pm 4.5^{a}$ & $26.1 \pm 3.7$ & $28.7 \pm 3.5$ \\
\hline $\begin{array}{l}\text { Smoking pack } \\
\text { [years] }\end{array}$ & $49.6 \pm 20.4^{a}$ & $42.3 \pm 18.9^{b}$ & 0 \\
\hline Peak $\mathrm{VO}_{2}[\mathrm{l} / \mathrm{min}]$ & $0.99 \pm 0.5^{a}$ & $1.4 \pm 0.3^{b}$ & $2.0 \pm 0.4$ \\
\hline $\mathrm{FEV}_{1}[\mathrm{I}]$ & $1.63 \pm 0.9^{a}$ & $1.7 \pm 0.5^{b}$ & $3.8 \pm 0.8$ \\
\hline $\mathrm{FEV}_{1}(\%$ predicted $)$ & $54.0 \pm 27.4^{a, c}$ & $60.7 \pm 14.7^{b}$ & $123.9 \pm 15.9$ \\
\hline FVC (\% predicted) & $97.4 \pm 24.2^{\mathrm{a}}$ & $99.0 \pm 17.2^{b}$ & $130.8 \pm 16.7$ \\
\hline $\mathrm{FEV}_{1} / \mathrm{FVC}$ & $42.2 \pm 15.3^{a}$ & $48.8 \pm 10.7^{b}$ & $79.5 \pm 6.8$ \\
\hline $\begin{array}{l}\mathrm{FEF}_{25-75} \\
\text { (\% predicted) }\end{array}$ & $19.0 \pm 17.9^{a}$ & $19.0 \pm 10.4^{b}$ & $102.9 \pm 28.3$ \\
\hline $\begin{array}{l}\text { Physical } \\
\text { functioning }\end{array}$ & $51.1 \pm 28.7 \mathrm{a}, \mathrm{c}$ & $74.0 \pm 21.1$ & $87.1 \pm 17.7$ \\
\hline $\begin{array}{l}\text { Difficulty in role } \\
\text { playing }\end{array}$ & $51.9 \pm 38.8^{a}$ & $65.1 \pm 44.8$ & $91.2 \pm 26.9$ \\
\hline Pain & $79.0 \pm 26.8$ & $83.6 \pm 20.8$ & $81.0 \pm 19.9$ \\
\hline General health & $51.3 \pm 26.3$ & $56.8 \pm 16.1$ & $69.7 \pm 15.6$ \\
\hline Vitality & $61.9 \pm 21.0$ & $73.1 \pm 13.6$ & $77.8 \pm 15.2$ \\
\hline Social functioning & $72.6 \pm 19.6$ & $89.7 \pm 13.4$ & $85.9 \pm 9.6$ \\
\hline $\begin{array}{l}\text { Emotional } \\
\text { well-being }\end{array}$ & $51.2 \pm 22.2$ & $60.6 \pm 29.1$ & $69.0 \pm 27.6$ \\
\hline Mental health & $63.7 \pm 23.7 c$ & $79.6 \pm 14.2$ & $71.1 \pm 13.3$ \\
\hline
\end{tabular}

in the literature $[6,7,9]$. Consistent with the previous studies, neuropathic involvement was axonal and predominantly sensory with milder involvement of motor nerves in our study. Faden et al. reported electrophysiological evidence of peripheral nerve dysfunction in 20 (87\%) of 23 patients with COPD who were active smokers throughout the study [6]. Kayacan et al. reported PNP at an incidence of $93.8 \%$ in 19 severe to very severe and 13 mild to moderate COPD patients. Nineteen of the severe to very severe COPD patients were also hypoxemic in their study population [7]. Agrawal et al. studied 30 smoker COPD patients and found that $17 \%$ of patients had PNP which was related to habits of smoking and the duration of illness, although no data about COPD stages of patients were provided in their study [9]. In our study all of the patients had mild to very severe COPD and all were ex-smokers. In addition, severity of airway obstruction was related to the presence of PNP, suggesting that PNP was related to severity of disease. Considering all these data, we suggest that different reported PNP frequencies of these studies could be due to the variety of COPD stages, hypoxemia and smoking status of the study populations.

Some studies have reported that smoking could be a factor for development of PNP in COPD patients $[6,9]$. Nevertheless, we found no difference between patients with PNP and without in terms of smoking exposure in comparison to the literature. Additionally, presence of PNP was related to the severity of disease, which was measured by $\mathrm{FEV}_{1}$ in our study. Other possible causes of PNP were also excluded due to the exclusion criteria of our study. Hence, we suggest that an inflammatory process spilling over into the systemic circulation $[5,17]$ might be a contributing factor for development of PNP.

Although mechanisms of exercise limitation have been researched in several studies [22-31], the clinical importance of peripheral neuropathy in the pathogenesis of decreased exercise capacity has not been investigated previously in COPD patients. Peripheral neuropathy generally consists of the triad of sensory changes, hyporeflexia and distal and/or proximal muscle weakness resulting in decreased exercise capacity of patients. Certain types of neuropathy may show widespread sensory symptoms, others may begin with more prominent proximal weakness, and mild cases may be subclinical. In the present study, peak $\mathrm{VO}_{2}$ was found to be significantly lower in COPD patients than in healthy subjects. Moreover, peak $\mathrm{VO}_{2}$ was more significantly decreased in COPD patients with PNP than in patients without PNP. Peak $\mathrm{VO}_{2}$ was also related to the presence of PNP and severity of disease in our COPD patients. Based on these results, we suggest that PNP may be a systemic effect of COPD which could be a contributing factor to the decreased exercise capacity of these patients.

Some studies have reported that health related quality life of COPD patients decreased due to [11, $32,33]$ numerous factors including dyspnea, severity of airway obstruction, hypoxemia, fatigue, muscle wasting, exercise limitation and environmental factors [33-36]. In our study the population life quality score was lower in patients with COPD who did not have any clinical symptoms of polyneuropathy than in healthy subjects. Furthermore, the decrease in quality of life scores was significant, especially in patients with PNP versus without. For this reason, we believe that even if the patients with COPD do not have any complaint suggesting neuropathic involvement, an electrophysiological study should be conducted to rule out PNP.

Certain markers of systemic inflammation, such as C-reactive protein (CRP), tumour necrosis factor $\alpha$ (TNF- $\alpha$ ) and interleukin 6 (IL-6), have been shown 
to be elevated in stable patients with COPD in several studies [5, 15, 17, 37-39]. In addition, systemic inflammation was found to be related to systemic effects of COPD patients. Therefore, it could be hypothesized that PNP could be a result of systemic inflammation in these patients. There is a single study researching the relation between inflammatory cytokines and PNP, which found no relation between peripheral nervous system involvement and proinflammatory cytokines such as TNF- $\alpha$, IL-6, insulin-like growth factor 1 (IGF-1) and CRP in COPD patients [40]. Although forty COPD patients were included in that study, PNP was detected in only 16 of the COPD patients. Hence, the authors declared that they could not compare patients with and without neuropathy due to the limited number of patients with neuropathy. Therefore, we suggest that their study may not reflect the relation between systemic inflammation and neurophysiological effects of COPD. Further studies are needed to research the relation between severity of inflammation and peripheral nervous system involvement in a larger number of COPD patients with PNP to support our hypothesis.

In conclusion, COPD is associated with numerous and significant systemic effects that impact a wide range of extrapulmonary tissues and organ systems. PNP as one of the complications of COPD related to poor life quality and exercise limitation should be investigated and treatment modalities for PNP can be recommended to these patients to improve exercise capacity and quality of life.

The number of patients enrolled is low. The distribution of the patients with regard to severity of COPD is not uniform. Such factors make it difficult to reach a firm conclusion. We also could not evaluate the role of systemic inflammation markers on PNP and quality of life in these patients. An additional control group of subjects with PNP was not included in the study. Thus we could not determine the effects of PNP on $\mathrm{FEV}_{1}$ and exercise capacity in healthy control subjects. Further studies and observations with larger numbers of subjects are needed to explore these associations.

\section{References}

1. Global Initiative for chronic obstructive lung disease. Global Strategy for the Diagnosis, Management, and Prevention of Chronic Obstructive Pulmonary Disease. NHLBI/WHO Workshop Report. US Department of Health and Human Services. Public Health Service, National Institutes of Health, National Hearth, Lung and Blood Institute. NIH Publication No. 2701, 2001.

2. Agusti A. Systemic effects of chronic obstructive pulmonary disease: what we know and what we don't know (but should). Proc Am Thorac Soc 2007; 4: 522-5.

3. Barnes PJ, Celli BR. Systemic manifestations and comorbidities of COPD. Eur Respir J 2009; 33: 1165-85.

4. O'Donnell DE. Exercise limitation and clinical exercise testing in chronic obstructive pulmonary disease. In:
Cardiovascular and respiratory system responses and limitations to exercise. Clinical exercise testing. Weissman IM, Zeballos RJ (eds). Karger AG, Basel 2002; 138-58.

5. Agusti AG, Noguera A, Sauleda J, Sala E, Pons J, Busquets X. Systemic effects of chronic obstructive pulmonary disease. Eur Respir J 2003; 21: 347-60.

6. Faden A, Mendoza E, Flynn F. Subclinic neuropathy associated with chronic obstructive pulmonary disease. Possible pathologic role of smoking. Arch Neurol 1981; 38: 639-42.

7. Kayacan O, Beder S, Deda G, Karnak D. Neurophysiological changes in COPD patients with chronic respiratory insufficiency. Acta Neurol Belg 2001; 101: 160-5.

8. Nowak D, Brüch M, Arnaud F, et al. Peripheral neuropathies in patients with chronic obstructive pulmonary disease: a Multicenter Prevalence Study. Lung 1990; 168: 43-51.

9. Agrawal D, Vohra R, Gupta PP, Sood S. Subclinical peripheral neuropathy in stable middle-aged patients with chronic obstructive pulmonary disease. Singapore Med J 2007; 48: 887-94.

10. Pellegrino R, Viegi G, Brusasco V, et al. Interpretative strategies for lung function tests. Eur Respir J 2005; 26: 948-68.

11. Mahler DA, Mackowiak JI. Evaluation of the short form 36 item questionnaire to measure health related quality of life patients with COPD. Chest 1995; 107: 1585-9.

12. Miller MR, Hankinson J, Brusasco V, et al. Standardisation of spirometry. Eur Respir J 2005; 26: 319-38.

13. Wanger J, Clausen JL, Coates A, et al. Standardisation of the measurement of lung volumes. Eur Respir J 2005; 26: 511-22.

14. Wasserman K, Hansen JE, Sue DY, Whipp BJ, Casaburi R. Principles of exercise testing and interpretation. 3rd ed. Lippincott Williams \& Wilkins, Baltimore 1999; 10.

15. Kaddah S, Rashed L, Obaia E, Sabry D. A preliminary study: matrix metalloproteinase expression as an indicator of the hazards of shisha (nargila) smoking. Arch Med Sci 2009; 5: 570-6.

16. Gan WQ, Man SF, Senthilselvan A, Sin DD. Association between chronic obstructive pulmonary disease and systemic inflammation: a systematic review and a metaanalysis. Thorax 2004; 59: 574-80.

17. Vernooy JH, Küçükaycan M, Jacobs JA, et al. Local and systemic inflammation in patients with chronic obstructive pulmonary disease: soluble tumor necrosis factor receptors are increased in sputum. Am J Respir Crit Care Med 2002; 166: 1218-24.

18. Rabinovich RA, Figueras M, Ardite E, et al. Increased tumour necrosis factor-alpha plasma levels during moderate-intensity exercise in COPD patients. Eur Respir J 2003; 21:789-94.

19. Takabatake N, Nakamura $\mathrm{H}$, Abe $\mathrm{S}$, et al. The relationship between chronic hypoxemia and activation of the tumor necrosis factor-alpha system in patients with chronic obstructive pulmonary disease. Am J Respir Crit Care Med 2000; 161: 1179-84.

20. Palange P, Testa U, Huertas A, et al. Circulating haemopoietic and endothelial progenitor cells are decreased in COPD. Eur Respir J 2006; 27: 529-41.

21. Gunen $\mathrm{H}$, Hacievliyagil SS, Yetkin O, et al. Prevalence of COPD: first epidemiological study of a large region in Turkey. Eur J Intern Med 2008; 19: 499-504.

22. Giardino ND, Curtis JL, Andrei AC, et al. Anxiety is associated with diminished exercise performance and quality of life in severe emphysema: a cross-sectional study. Respir Res 2010; 11: 29. 
23. Watz H, Waschki B, Boehme C, et al. Extrapulmonary effects of chronic obstructive pulmonary disease on physical activity: a cross-sectional study. Am J Respir Crit Care Med 2008; 177: 743-51.

24. Agustí AG, Sauleda J, Miralles C, et al. Skeletal muscle apoptosis and weight loss in chronic obstructive pulmonary disease. Am J Respir Crit Care Med 2002; 166: 485-9.

25. Celli BR, Cote CG, Marin JM, et al. The body-mass index, airflow obstruction, dyspnea, and exercise capacity index in chronic obstructive pulmonary disease. N Engl J Med 2004; 350: 1005-12.

26. Horwich TB, Fonarow GC, Hamilton MA, MacLellan WR, Borenstein J. Anemia is associated with worse symptoms, greater impairment in functional capacity and a significant increase in mortality in patients with advanced heart failure. J Am Coll Cardiol 2002; 39: 1780-6.

27. Barreiro E, Schols AM, Polkey MI, et al. Cytokine profile in quadriceps muscles of patients with severe COPD. Thorax 2008; 63: 100-7.

28. O'Donnell DE, Laveneziana P. Dyspnea and activity limitation in COPD: mechanical factors. COPD 2007; 4: 225-36.

29. Supinski GS, Callahan LA. Free radical-mediated skeletal muscle dysfunction in inflammatory conditions. J Appl Physiol 2007; 102: 2056-63.

30. Gosker HR, Bast A, Haenen GR, et al. Altered antioxidant status in peripheral skeletal muscle of patients with COPD. Respir Med 2005; 99: 118-25.

31. O'Donnell DE. Exercise limitation and clinical exercise testing in chronic obstructive pulmonary disease. In: Cardiovascular and respiratory system responses and limitations to exercise. Clinical exercise testing. Weissman IM, Zeballos RJ (eds). Karger AG, Basel 2002; 138-58.

32. Spencer S, Calverley PMA, Burger PS, Jones PW; ISOLDE study group. Health status deterioration in patients with chronic obstructive pulmonary disease. Am J Respir Crit Care 2001; 163: 122-8.

33. Hajiro T, Nishimura K, Tsukino M, et al. A comparision of the level of dyspnea vs disease severity in indicating the health related quality of life with COPD. Chest 1999; 116: 1632-7.

34. Oga T, Tsukino M, Sato S, Hajiro T. Analysis of the factors related to mortality in chronic obstructive pulmonary disease: role of exercise capacity and health status. Am J Respir Crit Care Med 2003; 167: 544-9.

35. Okubadejo AA, Paul EA, Jones PW, Wedzicha JA. Quality of life in patients with chronic obstructive pulmonary disease and severe hypoxemia. Thorax 1996; 51: 44-7.

36. Scherer TA, Spengler CM, Owassapian D, Imhof E, Boutellier U. Respiratory muscle endurance training in chronic obstructive pulmonary disease: impact on exercise capacity, dyspnea, and quality of life. Am J Respir Crit Care Med 2000; 162: 1709-14.

37. Rutter MK, Meigs JB, Sullivan LM, D'Agostino RB Sr, Wilson PW. C-reactive protein, the metabolic syndrome, and prediction of cardiovascular events in the Framingham Offspring Study. Circulation 2004; 110: 380-5.

38. Hamid YH, Rose CS, Urhammer SA, et al. Variations of the interleukin-6 promoter are associated with features of the metabolic syndrome in Caucasian Danes. Diabetologia 2005; 48: 251-60.

39. Karadag F, Karul AB, Cildag O, Yilmaz M, Ozcan H. Biomarkers of systemic inflammation in stable and exacerbation phases of COPD. Lung 2008; 186: 403-9.

40. Oncel C, Baser S, Cam M, et al. Peripheral neuropathy in chronic obstructive pulmonary disease. COPD 2010; 7 : 11-6. 